\title{
Design de Malhas Multifuncionais para Utilização em Vestuário Desportivo
}

Design of multifunctional weft-knitted fabrics for sport clothing

\section{Araguacy Paixão Almeida Filgueiras}

Doutora em Engenharia Têxtil pela Universidade do Minho-PT aradesign@vol.com.br

Maria do Socorro de Araújo

Especialização e Mestrado em Design e Marketing do Vestuário - University of Minho msdesigne@gmail.com 


\title{
Design de Malhas Multifuncionais para Utilização em Vestuário Desportivo
}

\author{
Design of multifunctional weft-knitted fabrics for sport clothing
}

\section{Araguacy Paixão Almeida Filgueiras e Maria do Socorro de Araújo}

\section{Resumo}

Durante a realização de atividades físicas, o esforço realizado pelo corpo humano faz libertar suor e provoca cansaço, fatores que, combinados com outros, afetam diretamente o desempenho. A ciência e a tecnologia, a serviço da sociedade, têm desenvolvido e apresentado produtos para a área desportiva com as mais variadas características e propriedades, obtidas a partir da transdisciplinaridade entre as várias áreas do conhecimento, com vista à maximização do rendimento dos atletas. $\mathrm{O}$ vestuário assume particular importância neste domínio, onde fatores como peso, transferência de calor/umidade e estrutura podem alterar a sua performance. Nesta perspectiva, o objetivo principal deste trabalho é apresentar resultado da otimização do design total de peças de vestuário desportivo, prevendo a sua aplicação ao desenvolvimento de uma Tshirt multifuncional para jogadores de futebol profissional. Experimentos realizados permitiram identificar estruturas e propriedades que podem ser aplicadas em determinadas zonas de contato da T-shirt com o corpo do atleta.

Palavras- chave: Vestuário desportivo. Multifuncionalidade. Design.

\section{Abstract}

While performing physical activities, the effort made by the human body is releasing sweat and causes fatigue factors combined with others directly affect performance. Science and technology in the service of society have developed and introduced products for the sports area with the most varied characteristics and properties derived from the transdisciplinary between the various areas of knowledge to maximizing the performance of athletes. The clothing is particularly important in this area where factors such as weight, heat transfer / moisture and structure can change your performance. In this perspective the main objective of this paper is presents results of the sportswear total design optimization providing for their application to the development of a multifunctional T-shirt for professional football players. Experiments have identified structures and properties that can be applied in certain contact zones $T$ shirt with the athlete's body.

Keywords: Sports clothing, Multifunctionality. Design 


\section{Introdução}

O crescente nível de exigência do mercado consumidor, a maior quantidade de informação disponível e o avanço da tecnologia, entre outros fatores, forçam a indústria, de um modo geral, a procurar inovações que não satisfaçam apenas aos anseios e desejos do consumidor, mas que, preferencialmente, se antecipem a estes (FILGUEIRAS, 2008, p.1).

É comum associar o estudo da tecnologia têxtil a produtos de vestuário de moda. No entanto, existem outros setores, não necessariamente de moda, com extrema importância tal como o setor do vestuário para o desporto ativo, que tem apresentado evoluções relevantes relativamente ao conforto, ao bem estar e ao desempenho do atleta (FILGUEIRAS, 2008, p.1.)

O mercado de vestuário desportivo não abrange apenas produtos para a prática profissional, devido ao "incentivo à prática de atividades físicas e ao uso de peças do vestuário desportivo no dia a dia", este tipo de vestuário atualmente tem sido utilizado por pessoas comuns, sendo, portando, um segmento cada vez mais competitivo (FILGUEIRAS, 2008. p.10). Assim, a oferta desses artigos tem aumentado porque designers e empresas, aliados à ciência e à tecnologia, trabalham na pesquisa de materiais "diferenciados para o lançamento de produtos inovadores a fim de conquistar cada vez mais uma clientela sedenta de novidades" (FILGUEIRAS, 2008 p. 12).

Por outro lado, as competições internacionais esportivas assumem proporções cada vez maiores. As estratégias mercantis são criativas, sendo alicerçadas em uma refinada e intensa publicidade. Segundo Melo et al (2011, p. 313) não seria equivocado considerar que, "nos dias de hoje, o consumo é um dos principais elementos constituintes desses espetáculos de cifras milionárias".

É importante conhecer o fenômeno do esporte moderno, desse modo de forma sucinta pode-se compreender, conforme Bourg e Gouguet (2005), o processo de mundialização do esporte como constituído por três períodos.

O primeiro período (1850-1914) caracteriza-se pela apropriação dos jogos da Idade Média, pelos ingleses do período da Revolução Industrial, nos quais competição e 
concorrência eram os valores predominantes. No segundo período (entre guerras e aos anos 1970) tem-se início a remuneração nos esportes e a difusão de transmissões esportivas via rádio, tal ação ativa sua dinâmica mercantil. No terceiro período (a partir dos anos 1980) os esportes de alto rendimento objetivam: comercialização, lucro, cientificismo e midiatização, os eventos se tornam de dimensões planetárias (BOURG e GOUGUET, 2005). Conforme Almeida et al (2008, p.1) a "relação dinheiro e esporte é um ciclo onde não se sabe se são as características peculiares do esporte que atraem o investimento financeiro ou se é a demanda da sociedade capitalista que envolve o esporte".

Neste contexto, o segmento desportivo tem beneficiado e absorvido os têxteis tecnológicos com maior intensidade que outros segmentos, proporcionando aos atletas melhor desempenho profissional, tornando o segmento mais competitivo e capaz de conquistar novos nichos de mercado. Desta forma, pode afirmar-se que o desporto constitui um segmento de elevada importância do setor têxtil uma vez que envolve, para além dos desportistas, os adeptos e o utilizador comum que utilizam na rua peças do vestuário destinadas à prática desportiva. O futebol destaca-se neste sentido, por ser uma modalidade bastante difundida em todo o mundo.

De acordo com Melo et al (2011, p. 313), entre os esportes, o futebol por sua popularidade e presença mundial tem direito a destaque pois, "basta dizer, a título de exemplo, que a FIFA tem mais associados do que a ONU". Para Helal e Gordon (2001, p. 99), "o futebol é um universo rico em imagens e representações da coletividade".

O desenvolvimento de peças de vestuário desportivo, nomeadamente a T-shirt para a atividade futebolística, insere-se na concepção de vestuário que fornece maior conforto ao atleta durante a atividade desportiva e, consequentemente, o leve ao melhor desempenho profissional, pela incorporação de fibras e estrutura avançadas. A interligação de diversas áreas com o setor têxtil proporciona uma transdisciplinaridade de conhecimentos em que não existe, praticamente, nenhuma disciplina científica que não contribua para o desenvolvimento de novos produtos e processos.

No setor têxtil e de confecção, a preocupação gira em torno do eixo homem vestuário - meio ambiente. Considerado um sistema, os três aspectos têm influência entre si, interagindo no que vai gerar a sensação de conforto ou desconforto do homem (FILGUEIRAS, 2008 p. 12). 
As características do vestuário são determinantes na sensação de conforto. As propriedades de transferência de calor e umidade dos têxteis são fatores que afetam o conforto e podem determinar a eficácia da funcionalidade que o produto pretende oferecer. Neste contexto, este trabalho direciona-se para o estudo e utilização destas propriedades no sentido de contribuir e oferecer o melhor conforto termofisiológico durante a atividade desportiva profissional. Este trabalho tem como objetivo apresentar resultados da otimização do design total de peças de vestuário desportivo, considerando a sua aplicação no desenvolvimento de uma T-shirt multifuncional para jogadores de futebol profissional. Os procedimentos metodológicos utilizados consistiram em pesquisa bibliográfica, identificação de material existente, aplicação de questionário e experimentos em laboratório. A partir da análise das propriedades de T-shirts já existentes no mercado e dos resultados obtidos em questionários aplicados a jogadores de futebol profissional, definiram-se as especificações da peça de vestuário a desenvolver, tendo como base a utilização de fibras funcionais e de estruturas de malha.

Sabendo que para o vestuário desportivo é indispensável um produto que corresponda às necessidades específicas do desportista e, uma vez que, durante as atividades desempenhadas são muitas as reações fisiológicas do corpo humano, verificase a pesquisa e o produto desenvolvido de elevada importância, pois o mercado desportivo de futebol profissional demanda para a confecção de suas T-shirts uma combinação de fibras que atuem pontualmente em resposta a essas reações fisiológicas e, também, aumente o desempenho dos seus atletas. Tendo sempre em vista a maximização do desempenho do atleta, tem-se destacado nos últimos tempos, no mercado desportivo, o desenvolvimento de artigos de vestuário para segmentos específicos, nomeadamente para o futebol. Das mais recentes inovações, podem citar-se as T-shirts junto ao corpo, sem costura (a junção das partes da peça é feita por termocolagem) e produzidas com materiais que favorecem o controle da umidade. Estas características, para além de satisfazerem e proporcionarem conforto ao utilizador funcionam igualmente como fortes fontes de estratégias de marketing, publicidade e venda.

A última geração de materiais fibrosos oferece características importantes para obtenção do objetivo proposto neste trabalho, contudo, a sua utilização não tem sido efetuada de forma otimizada. No sentido de aumentar a eficiência, o valor comercial e 
reduzir custos de comercialização, este trabalho teve maior relevância por aplicar os conceitos de "patchwork" e racionalização, otimizando o desempenho dos materiais fibrosos funcionais. Importante também, foi utilizar técnicas de produção inovadoras que maximizem o seu desempenho e, consequentemente, o dos atletas durante a competição, eliminando operações adicionais no processo de produção que, muitas vezes, criam áreas de desconforto no contacto com o corpo humano.

A análise bibliográfica efetuada permitiu concluir que os estudos científicos publicados sobre a temática da utilização de fibras funcionais em vestuário desportivo, são bastante escassos e, raramente apontam para conclusões claras que ajudem o designer a decidir acerca da distribuição das fibras no produto. Neste contexto, este trabalho pretende igualmente contribuir para o melhor conhecimento acerca do desempenho de fibras com funções específicas, principalmente no que concerne à interação entre as diversas funcionalidades e a otimização de misturas de fibras funcionais numa mesma peça de vestuário. Esta interface constitui, enfim, no conceito de otimização do design total de um produto do vestuário desportivo.

\section{O mercado do vestuário desportivo}

Em 2002 (SÁ \& SÁ, 2002) o mercado do desporto representava 3\% do comércio mundial. No entanto de acordo com David Rigby Associates, o consumo de têxteis no sportswear e em produtos e equipamentos teve um aumento significativo, algo em torno de $36 \%$ entre os anos de 2005 e 2010. Conforme os estudos, percebe-se que no mundo inteiro o PIB dos esportes tem crescido continuamente. Devido à crise das indústrias automobilística, bancária, de máquinas e equipamentos no Brasil, o setor de esportes teve participação expressiva para atenuar a recessão e o desemprego. A taxa anual do crescimento do PIB esportivo supera a do PIB brasileiro. A taxa média de crescimento anual do setor esportivo no Brasil no período de 2007 a 2011 foi de 7,1\%, enquanto que o PIB nacional cresceu cerca de 4,2\% (CASTELLANI FILHO, 2014). Em 2010 seu crescimento foi o maior de todos os anos anteriores, tendo taxa anual de 8,94\%, sua participação no PIB se elevou a 2,14\%. Nesse período o PIB dos esportes teve ganho de US\$ 45,35 bilhões de dólares, representando um recorde em termos locais e total significativo entre as 10 maiores economias do mundo. O Brasil ficou em oitavo lugar em 2010 (KASZNAR, 2013). 
Conforme Rodrigues (2014) a estimativa econômica é de que em 2016 a participação do setor de esportes no PIB nacional seja de aproximadamente 1,9\%. O futebol ocupa o maior índice, $53 \%$ do PIB esportivo brasileiro, sendo cerca de $0,8 \%$ do PIB nacional, ou seja, R \$ 36 bilhões, esses valores bem expressivos representam o PIB do Paraguai.

As pesquisas de mercado evidenciam que o desporto considerado como indústria de entretenimento está ligado a grandes audiências significando assim, um poderoso veículo midiático "propagador das marcas e de seus patrocinadores" (PAULICO, 2008, p. 118). Para Azevedo (2009, p.930), os agentes de marketing são responsáveis por estimular "o consumo dos produtos esportivos, fazendo com que a prática esportiva seja seguida por praticantes não profissionais e transferida para a prática de consumo de produtos esportivos", tal estímulo foi capaz de ampliar o mercado para bilhões de consumidores, o que inicialmente era direcionado apenas para "milhares de atletas de alto nível". Este mercado abrange o vestuário desportivo no segmento streetwear, aquele da rotina, para trabalho, lazer, e outras situações usuais. Surgiram outros segmentos como o skateswear e o beachwear, entre outros, que apresentam peças que podem ser usadas tanto na prática desportiva quanto no uso diário (ACCIOLLY, 2000; SÁ \& SÁ, 2002).

O desporto de competição, que ao longo do século passado foi cada vez mais profissionalizado, suscitou diferentes formas de consumo esportivo, dentre os quais o esporte escolar, o esporte de lazer, e o esporte para a saúde e atualmente tem sido percebido outro mercado, o da estética - que acrescentam bilhões de dólares anuais às atividades de produção, comércio e serviços relacionadas ao esporte em todo o mundo. No setor do desporto, destacam-se o vestuário, o calçado e os acessórios, como os principais artigos têxteis utilizados.

De acordo com Filgueiras (2008), para não serem imitadas pelos concorrentes e se manterem no mercado, as empresas buscam ser competitivas fazendo a reinvenção contínua de produtos e serviços, utilizando o potencial de conhecimento, competências e experiências da forma mais imaginativa e eficaz. Uma das alternativas é unir ciência e tecnologia com objetivo de lançar produtos com desempenho superior ao dos produtos já existentes no mercado. A permanência da empresa nesse mercado implica igualmente uma mudança nas dimensões intangíveis de competitividade, tais como o serviço ao 
cliente (antes, durante e após a venda), reputação e talento geral na forma como tudo é feito e apresentado (KOTLER, P. \& BES, 2004 e KOTLER, 2005).

Sabe-se que o utilizador final de produtos têxteis no mercado do desporto compreende atletas profissionais e amadores e o público em geral. Diante desta realidade, não são apenas as empresas conhecidas pela produção e comercialização de material desportivo, como Nike, Adidas, Puma, Reebok, e outras, mas grifes igualmente grandes, lojas de departamento (magazines, cadeias de lojas), dos quais se pode citar H\&M, MacModa, Diesel, Replay e TNG e estilistas como MacQueen, Christian Lacroix, Yohji Yamamoto, Stella McCartney, Dolce \& Gabanna e Davi Delfín que lançam nas suas coleções artigos inspirados nas atividades desportivas, incluindo peças desde moda casual até artigos de alto luxo.

\section{Materiais Têxteis usados na confecção do vestuário desportivo}

Há uma gama bastante diversificada de materiais têxteis utilizados nos diferentes tipos de desporto. As fibras e os tecidos de alto desempenho têm tido papel importante em vestuário desportivo, sendo cada vez mais utilizados produtos tecnicamente mais eficientes para atividades fisicamente mais exigentes. Assim, o mundo do desporto de alto rendimento tem sido marcado pelo desenvolvimento de vestuário com propriedades que permitam absorção e transporte de umidade, elasticidade, resistência, e que podem aumentar o desempenho dos atletas, como por exemplo, o vestuário produzido para melhorar o conforto térmico durante as provas. Este vestuário deixa passar o suor para a camada externa mantendo-se seca a camada interna que fica em contato direto com a pele (FILGUEIRAS, 2008). Para a identificação das fibras e tecidos ideais, estes são submetidos a ensaios rígidos para medição dessas propriedades. Assim, nestes estudos são verificados que as fibras naturais sendo absorventes e transportadora de umidade corporal, com ajustes adequados podem, por exemplo, ser produzidas com propriedades de resistência à água, ao vento e respiráveis.

As diferentes modalidades desportivas demandam roupas específicas, pois estão diretamente relacionadas com o ambiente no qual a atividade é realizada, com o tipo de esforço, energia gasta, intensidade e duração de movimentos com a prática despendida. 
Shishoo (2005) considera que o desempenho necessário em alguns produtos é obtido pelo equilíbrio das diferentes propriedades. Neste contexto, as fibras sintéticas são as preferidas para desportos muito ativos, uma vez que não retêm umidade, não se tornando, portanto, mais pesadas devido à absorção do suor, tal como acontece com o algodão. Este tipo de vestuário apresenta, por outro lado, melhor estabilidade dimensional. As fibras sintéticas satisfazem os principais requisitos do vestuário desportivo de alta tecnologia, ou seja, conservação da temperatura, resistência ao vento, baixa absorção de umidade e baixo peso, conforto e toque das fibras naturais, design e variedade de cores.

No entanto, as características ideais dos materiais têxteis usados para vestuário desportivo, necessárias ao melhor desempenho do desportista, são derivadas das fibras utilizadas, da construção do fio, do método de produção do tecido, dos processos de acabamento e, enfim, do design integral do produto, principalmente das tecnologias utilizadas. Os estudos têm demonstrado que maciez, leveza no toque, resistência mecânica ao uso, secagem rápida, estabilidade dimensional favorável, alta elasticidade e poder de recuperação, absorção do suor, respirabilidade e transporte da umidade são propriedades fundamentais às roupas para os desportistas (FILGUEIRAS, FANGUEIRO, RAPHAELLI 2008).

\section{Conceitos associados à teoria do conforto}

Atualmente o conforto é um dos requisitos essenciais para atrair o desejo do consumidor em produtos do vestuário (ARAÚJO, 2012). É um estado aprazível de conformidade fisiológica, psicológica e física entre o ser humano e o ambiente. Também pode ser considerado como a ausência de dor e de desconforto (SLATER, 1986; 1997).

No vestuário os aspectos sensoriais ou táteis, termofisiológicos e psicológicos se interagem (PIRES, 2008). Os aspectos sensoriais ou táteis são as sensações provocadas pelo contato do tecido com a pele e do ajuste da confecção com o corpo, que corresponde à modelagem, montagem e acabamento do produto. Para Sousa (2008), tais sensações estão diretamente relacionadas às respostas do organismo aos estímulos físicos causados pelo contato da roupa com o corpo. São fundamentais, nesse caso, as propriedades do material têxtil como a flexibilidade do tecido, maciez e rigidez. 
Aspectos termofisiológicos se referem à interferência do vestuário nos mecanismos do corpo, sobretudo como termorregulador. De acordo com Araújo (2009 p.32) “os elementos principais a serem considerados para uma análise do conforto termofisiológico são: microclima (temperatura do corpo entre a pele e a parte externa do vestuário), compressão do vestuário no corpo e o toque do tecido na pele". Cunha (2006) considera que o vestuário não apenas tem o papel de cobrir a pele, ele participa dinamicamente na interação com o corpo, sendo capaz de fazer a manutenção do balanço térmico, porque modifica a dissipação do calor e da umidade a partir da pele. Um tecido adequado para pessoas que vivem em clima muito quente e úmido e ou praticam atividade física em que haja muita dissipação de calor e suor deve permitir a respirabilidade da pele e manter em equilíbrio a temperatura do corpo.

Li (1998) e Broega e Silva (2010) afirmam que o conforto ergonômico é uma situação de harmonia física e mental. O conforto físico diz respeito às sensações despertadas pelo contato do tecido com a pele e do ajuste da confecção ao corpo, sem dificultar os seus movimentos. Por fim o conforto psicológico, sendo este totalmente subjetivo, remete ao bem-estar emocional no qual o consumidor sentir-se-á seguro, confortável em adquirir o produto e por este contemplar além dos valores estéticos e simbólicos, os quesitos de conforto já mencionados. No que diz respeito aos aspectos psicológicos e estéticos Barnad (2003) faz menção aos fatores ambientais, sociais, econômico, cultural e de estilo.

Pode-se dizer que a mensagem que o vestuário transmite está relacionada a questões como cultura, condição econômica, idade, sexo e gênero, status social, estilo próprio e atividade que o usuário desenvolve. Fatores estéticos como cor, design, aderência, modelagem, tamanho compatível, bom corte e caimento, são igualmente importantes, porque podem ser adaptados às várias exigências e estilos, dentre outros.

\section{Fisiologia do exercício e conforto}

Conforme comentado anteriormente, a compreensão do conforto é subjetiva por abranger aspectos psicológicos e fisiológicos individuais, variando então de individuo para individuo. O processo psicológico é um reflexo das sensações sensoriais. Já o processo físico tem relação com os estímulos que o vestuário e o ambiente propiciam ao corpo; o processo fisiológico compreende as reações fisiológicas que o corpo humano 
apresenta perante as mais diversas situações ambientais e de atividades. Nesse contexto, Broega e Silva (2010) reitera que a percepção final de conforto e desconforto é decorrente da interação entre estes aspectos em todo o sistema corpo-vestuárioambiente processados no cérebro.

Determinadas reações fisiológicas dos humanos são regidas pelo sistema termorregulador do corpo e dependem das condições a que este é submetido. A combinação dessas reações influencia diretamente o sistema termorregulador que trabalha para a manutenção do equilíbrio térmico do corpo humano (HALL e GUYTON, 2002).

O corpo humano quando funciona regularmente, está apto a desempenhar as suas atividades, que podem ser subdivididas em duas categorias: atividades externas e atividades basais internas. As atividades externas são aquelas desempenhadas conscientemente pelo homem por meio do seu trabalho ou de alguma atividade exercida. As atividades basais internas envolvem as que acontecem independentes da vontade humana, permitindo que os órgãos do corpo funcionem adequadamente.

A realização de atividades físicas intensas ou a exposição a ambientes quentes faz com que se inicie a secreção de suor formando um filme sobre a superfície do corpo. A proporção de área superficial sujeita à difusão de água através da pele diminui à medida que a sudação aumenta. Os dois fenômenos, sudação e difusão, não ocorrem simultaneamente na mesma região da pele.

Quando a perda de calor para o ambiente é limitada pela temperatura ambiental elevada, alta umidade ou roupas quentes, o calor produzido pela atividade muscular é uma séria ameaça à homeostase térmica, que pode ocasionar colapso ou até mesmo a morte. Daí a importância do equilíbrio entre o homem, o vestuário e o ambiente. O equilíbrio entre o homem e o meio no qual interage ocorre mediante a procura de ações que assegurem o conforto térmico. O ser humano não possui meios naturais para promover o equilíbrio térmico entre seu corpo e o meio ambiente para suportar as mais diversas variações climáticas. Esta interação está vinculada, entre outras ações, à atividade e ao vestuário que utiliza. Assim, o vestuário atua como isolante térmico para limitar as perdas de calor do corpo, a poupar sua energia interna e a proporcionar melhores sensações de bem-estar (FILGUEIRAS, 2008). 


\section{Procedimentos Metodológicos}

A metodologia adotada neste estudo enquadra-se num campo exploratório de caráter qualitativo e quantitativo. Foram adotados pesquisa bibliográfica, aplicação de questionários e ensaios laboratoriais. Foi realizada identificação do material existente no mercado, suas propriedades e características. As experiências realizadas em laboratório seguiram à seleção das fibras, preparação das malhas a ensaiar e produção de malhas pré-definidas na estrutura determinada, e foram considerados os parâmetros prédefinidos dentro das funcionalidades requeridas (capilaridade, permeabilidade, condutibilidade, flexibilidade e cair). Por fim, a produção de T-shirt multifuncional.

No sentido de estudar o desempenho de malhas produzidas com fios à base de fibras com as funcionalidades requeridas para a aplicação selecionada, foram produzidas diversas amostras em malha jersey simples, combinando fibras bases com fibras funcionais em proporções diversificadas. Além disso, foi igualmente efetuada uma análise de desempenho de malhas de dupla face em jersey vanizado, contendo fibra funcional na face interna e fibra base na face externa.

\section{Análise e discussões dos resultados}

\section{Análise de materiais}

Com o objetivo de estudar as características e propriedades de T-shirts existentes no mercado para a prática de futebol profissional, foram selecionados alguns exemplares de marcas conhecidas e, em seguida, analisados em termos do seu desempenho em diversos parâmetros relacionados com o conforto. Buscou-se estudar T-shirts com diferentes estruturas de malha, com e sem forro, com e sem tecnologia Climacool ${ }^{\circledR}$, obtendo, assim, valores de referência para as propriedades em análise.

A caracterização das malhas utilizadas, assim como todos os procedimentos relativamente aos ensaios realizados, seguiram às Normas aplicáveis, tendo incluído os parâmetros de debuxo e propriedades dimensionais - espessura, comprimento de laçada, fator de cobertura, massa linear dos fios e o número de colunas e fileiras $/ \mathrm{cm}$.

Quanto ao debuxo verifica-se que, embora todas as estruturas sejam produzidas utilizando dois sistemas de agulhas combinando laçadas flutuantes com laçadas normais, resultam diferentes estruturas. No primeiro tipo, a célula estrutural do ponto (CEP) é composta por 6 alimentações utilizando dois fios; o segundo tipo também é 
produzido com seis alimentações em dois fios; e, o último, é composto por vinte e um alimentadores, produzido por três fios.

Mesmo que todos os fios sejam produzidos em 100\% poliéster, os fios diferem no brilho, o que favorece a aparência brilhante na face exterior da T-shirt. Verificou-se que algumas amostras apresentam fios, comprimentos de laçadas e massa linear semelhantes, enquanto que o peso apresenta sensíveis diferenças

Foram analisadas, nestas amostras, as propriedades de controle da umidade Capilaridade horizontal, capilaridade vertical, molhagem e perda de umidade em três níveis de temperatura; propriedades térmicas verificadas no aparelho Togmeter e no manequim térmico; propriedades físicas - Cair, rigidez à flexão e resistência multidirecional; e propriedades de permeabilidade - ao ar e ao vapor d'água.

Os resultados obtidos permitiram constatar que debuxos com quantidade de fileiras tricotadas nos dois sistemas de agulhas favorecem a capilaridade horizontal e vertical. Por outro lado, levam a que a malha apresente piores desempenhos em termos de perda de umidade. O debuxo de uma malha pode influenciar fortemente o seu nível de capilaridade e assim o líquido penetrar mais facilmente nos espaços existentes entre os fios. A estrutura do debuxo mais simples em relação às demais, a presença de laçadas flutuantes e a quantidade fios diferentes podem ser fatores que expliquem esse comportamento. O tipo de material e a espessura são fatores determinantes das propriedades térmicas de um produto têxtil, sendo que o debuxo também pode interferir nestes resultados, assim como também acabamentos especiais que o material tenha recebido. Mesmo que as amostras sejam produzidas em 100\% PES, verificou-se diferença no isolamento térmico destas. A existência de camada dupla faz aumentar a espessura do material, fornecendo o maior isolamento térmico.

O debuxo, os interstícios da malha, o fator de cobertura e a espessura podem ser considerados aspectos relevantes no que concerne à propriedade de permeabilidade ao vapor de água, favorecendo melhores resultados. Assim como a permeabilidade ao vapor, a permeabilidade ao ar também depende das características relativas à estrutura e ao fator de cobertura da malha. O melhor desempenho foi uma amostra de malha aberta, com menor fator de cobertura.

A capacidade de cair e a rigidez à flexão de um material têxtil são influenciadas ou definidas pelo debuxo, fator de cobertura, tipo e estrutura do fio, massa e acabamentos. 
O conforto ideal necessário para o usuário reúne as melhores características de cada uma das T-shirts. Assim, têm-se resultados que poderão ser melhorados a fim de que uma T-shirt seja projetada e construída com propriedades adequadas ao melhor conforto estético, psico e termofisiológico do atleta.

\section{Análise dos questionários}

O questionário desenvolvido com questões fechadas e abertas foi aplicado junto a jogadores de futebol profissional, e é estruturado nas seguintes seções: - Especificações básicas sobre as características dos inquiridos ${ }^{1}$; - Questões referentes às características observadas durante a utilização do equipamento ${ }^{2} ;-$ Opinião e sugestões relativamente ao design da T-shirt.

Inicialmente foram estudadas as T-shirts utilizadas pelos inquiridos, em suas características e propriedades, sob os mesmos aspectos dos ensaios anteriores. A amostra de jogadores compreende profissionais com idade de 17 a 37 anos, com maior concentração entre 23 e 26 anos. Constata-se que mais de $50 \%$ dos atletas participaram em tempo integral na atividade durante a avaliação das T-shirts. Os inquiridos apresentam redução no grau de conforto à medida que o tempo passou.

Tendo em conta os resultados obtidos nos questionários, o desenvolvimento da nova T-shirt, objetivo desse estudo, deve basear-se nas referidas necessidades:

- Maior leveza;

- Controle constante e contínuo da umidade;

- Controle da temperatura para incremento do conforto;

- Adaptação ao corpo;

- Diminuição do incômodo das costuras;

- Diminuição do desconforto provocado pela inclusão da publicidade;

- Melhoria do design estético.

Assim, a nova T-shirt deve contemplar o uso de material avançado que possa satisfazer, sobretudo, a necessidade de gestão da umidade, mas também, garantir que a estrutura a utilizar potencie esse fato. Por outro lado é importante notar que ao

\footnotetext{
${ }^{1}$ Idade, posição que ocupa na equipe, o tempo de uso da T-shirt em avaliação e se usa T-shirt interior. 2 Absorção e libertação do suor pela T-shirt, nível e locais de sudação, circulação de ar entre o corpo e a T-shirt e sua resistência, sensações de toque, flexão e características de ergonomia relativamente à conformabilidade da T-shirt ao corpo e aos seus movimentos.
} 
nível da seleção de tecnologia para a produção da T-shirt se deverá selecionar tecnologia sem costura que proporcione simultaneamente o ajustamento da T-shirt ao corpo do atleta, com design arrojado. Estas considerações apontam para o uso da tecnologia Seamless, utilizando fibras e estruturas avançadas. É importante estudar, portanto, a integração, composição e o desempenho das fibras funcionais e da estrutura quanto aos diversos aspectos da T-shirt ensaiada.

\section{Desenvolvimento de produto}

\subsection{Definição dos materiais}

Nesta fase do trabalho foi realizado um estudo sobre o comportamento de malhas produzidas com fibras que contêm as funcionalidades necessárias ao desempenho de T-shirts para jogadores de futebol: gestão e controle da umidade, controle térmico e bioatividade. Para o desenvolvimento das malhas funcionais, utilizou-se uma fibra de base combinada, em várias percentagens, com as fibras funcionais no sentido de avaliar a influência das misturas nas propriedades das malhas. As fibras de base selecionadas foram o poliéster (PES) e o polipropileno (PP), que foram misturadas com fibras funcionais para garantirem estas funcionalidades, nomeadamente PBT (polibutileno tereftalato), poliamida Aquator ${ }^{\circledR}$, viscose Outlast ${ }^{\circledR}$, poliéster Dry release ${ }^{\circledR}$ e poliéster Bioactive ${ }^{\circledR 3}$, cujas especificações podem ser visualizadas nas Figuras 1 e 2. Os ensaios realizados sobre estas malhas incluem transporte de umidade no sentido das colunas e das fileiras, libertação da umidade, permeabilidade ao ar e ao vapor de água, propriedades térmicas, cair e rigidez à flexão. Ao final desta análise efetuada permite-se retirar as conclusões a seguir.

\footnotetext{
${ }^{3}$ Abreviaturas: Aquator ${ }^{\circledR}($ AQT $)$, viscose Outlast ${ }^{\circledR}(\mathrm{OUT})$, poliéster Dry release ${ }^{\circledR}(\mathrm{DR})$ e poliéster Bioactive $^{\circledR}$ (BA)
} 
Figura 1 - Especificações das malhas jersey - base poliéster

\begin{tabular}{|c|c|c|c|c|c|c|c|}
\hline \multicolumn{8}{|c|}{ Combinações com PES } \\
\hline Combinaçôes & $\begin{array}{c}\text { Composição } \\
(\%)\end{array}$ & $\begin{array}{c}\text { Espessura } \\
(\mathrm{mm})\end{array}$ & $\begin{array}{l}\text { Massa } \\
\left(\mathrm{g} / \mathrm{m}^{2}\right)\end{array}$ & $\begin{array}{c}\text { Grau de } \\
\text { aperto (k) }\end{array}$ & $\begin{array}{c}\mathrm{N}^{\circ} \\
\text { colunas } \\
/ \mathrm{cm}\end{array}$ & $\begin{array}{c}\mathrm{N}^{*} \\
\text { filciras } \\
/ \mathrm{cm}\end{array}$ & $\begin{array}{c}\text { Comp.de } \\
\text { laçada } \\
\text { (cm) }\end{array}$ \\
\hline \multirow{5}{*}{$\begin{array}{l}\text { Poliéster/ } \\
\text { PBT }\end{array}$} & $83 \% / 17 \%$ PES/PBT & 1.65 & 296.49 & 15.99 & 8 & 16 & 0,4276 \\
\hline & $66 \% / 34 \%$ PES/PBT & 1.58 & 308.40 & 15.93 & 10 & 14 & 0,4292 \\
\hline & $50 \% / 50 \%$ PES/PBT & 1.57 & 321.03 & 15.93 & 9 & 16 & 0,4294 \\
\hline & $34 \% / 66 \%$ PES/PBT & 1.60 & 339.23 & 16.26 & 9 & 16 & 0,4206 \\
\hline & $17 \% / 83 \%$ PES/PBT & 1.61 & 343.84 & 16.08 & 9 & 17 & 0,4254 \\
\hline \multirow{4}{*}{$\begin{array}{l}\text { Poliéster I } \\
\text { Aquator }\end{array}$} & $83 \% / 17 \%$ PES/AQT & 1.72 & 319.25 & 15.49 & 8 & 15 & 0,4388 \\
\hline & 66\%/34\% PES/AQT & 1.82 & 353.40 & 15.31 & 8 & 15 & 0,4468 \\
\hline & $50 \% / 50 \% \mathrm{PES} / \mathrm{AQT}$ & 1.97 & 360.43 & 14.89 & 7 & 14 & 0.4592 \\
\hline & 34\%/66\% PES/AQT & 2.06 & 414.23 & 14.62 & 8 & 13 & 0,4678 \\
\hline \multirow{3}{*}{$\begin{array}{l}\text { Poliéster/ } \\
\text { Bloactive }\end{array}$} & $66 \% / 34 \%$ PES/BA & 1.87 & 384.02 & 15.96 & 7 & 14 & 0.5762 \\
\hline & $50 \% / 50 \%$ PES/BA & 2.29 & 319.48 & 15.34 & 8 & 12 & 0,5098 \\
\hline & $17 \% / 83 \% \mathrm{PES} / \mathrm{BA}$ & 3.13 & 359.01 & 15.83 & 7 & 11 & 0.5490 \\
\hline \multirow{3}{*}{$\begin{array}{c}\text { Poliéster / } \\
\text { Outlast }\end{array}$} & 66\%/34\% PES/OUT & 1.98 & 345.88 & 16.37 & 7 & 11 & 0,5618 \\
\hline & $50 \% / 50 \%$ PES/OUT & 1.78 & 271.25 & 15.59 & 8 & 13 & 0,5016 \\
\hline & $17 \% / 83 \%$ PES/OUT & 1.54 & 266.52 & 15.53 & 7 & 11 & 0,5598 \\
\hline \multirow{4}{*}{$\begin{array}{l}\text { Poliéster / } \\
\text { Dry release }\end{array}$} & $66 \% / 34 \% \mathrm{PES} / \mathrm{DR}$ & 1.56 & 328.94 & 15.26 & 7 & 11 & 0,5032 \\
\hline & $50 \% / 50 \% \mathrm{PES} / \mathrm{DR}$ & 1.42 & 249.69 & 14.95 & 8 & 13 & 0,4404 \\
\hline & $34 \% / 66 \%$ PES/DR & 2.38 & 309.27 & 15.46 & 7 & 12 & 0,5144 \\
\hline & $17 \% / 83 \%$ PES/DR & 2.32 & 229.57 & 15.38 & 9 & 13 & 0.4493 \\
\hline
\end{tabular}

Fonte: Dados da pesquisa

Figura 2 - Especificações das malhas jersey - base polipropileno

\begin{tabular}{|c|c|c|c|c|c|c|c|}
\hline \multicolumn{8}{|c|}{ Combinações com PP } \\
\hline Combinaçōes & $\begin{array}{c}\text { Composiçåo } \\
(\%)\end{array}$ & $\begin{array}{c}\text { Espessura } \\
(\mathrm{mm})\end{array}$ & \begin{tabular}{|l|} 
Massa \\
$\left(\mathrm{g} / \mathrm{m}^{2}\right)$
\end{tabular} & $\begin{array}{c}\text { Grau de } \\
\text { aperto (k) }\end{array}$ & \begin{tabular}{|c|}
$\begin{array}{c}\text { Colunas } \\
/ \mathrm{cm}\end{array}$ \\
\end{tabular} & $\begin{array}{c}\text { Fileiras } \\
/ \mathrm{cm}\end{array}$ & $\begin{array}{c}\mathrm{Lu} \\
(\mathrm{cm})\end{array}$ \\
\hline \multirow{5}{*}{$\begin{array}{l}\text { Polipropileno / } \\
\text { PBT }\end{array}$} & $83 \% / 17 \%$ PP/PBT & 1,79 & 274.08 & 14,5 & 8 & 15 & 0,4716 \\
\hline & $66 \% / 34 \%$ PP/PBT & 2,19 & 300.01 & 14,73 & 8 & 15 & 0,4642 \\
\hline & $50 \% / 50 \%$ PP/PBT & 2,21 & 321.95 & 15,4 & 7 & 13 & 0,4440 \\
\hline & $34 \% / 66 \%$ PP/PBT & 1,78 & 334.57 & 16,04 & 9 & 16 & 0,4264 \\
\hline & $17 \% / 83 \%$ PP/PBT & 2,23 & 376.35 & 15,44 & 9 & 17 & 0,4428 \\
\hline \multirow{4}{*}{$\begin{array}{c}\text { Polipropileno / } \\
\text { Aquator }\end{array}$} & $83 \% / 17 \%$ PP/AQT & 1,73 & 318.05 & 14,74 & 8 & 15 & 0,4640 \\
\hline & $66 \% / 34 \%$ PP/AQT & 1,89 & 375.02 & 14,85 & 8 & 14 & 0,4604 \\
\hline & $50 \% / 50 \%$ PP/AQT & 1,87 & 426.48 & 14,65 & 9 & 15 & 0,4668 \\
\hline & $34 \% / 66 \% \mathrm{PP} / \mathrm{AQT}$ & 1,83 & 457.47 & 14,46 & 8 & 14 & 0,4728 \\
\hline \multirow{3}{*}{$\begin{array}{l}\text { Polipropileno / } \\
\text { Bioactive }\end{array}$} & $66 \% / 34 \%$ PP/BA & 2,39 & 309.55 & 14,61 & 7 & 10 & 0,5354 \\
\hline & $50 \% / 50 \%$ PP/BA & 2,39 & 316.29 & 14,86 & 7 & 12 & 0,6006 \\
\hline & $17 \% / 83 \%$ PP/BA & 2,81 & 364,31 & 15,08 & 8 & 10 & 0,5764 \\
\hline \multirow{3}{*}{$\begin{array}{l}\text { Polipropileno / } \\
\text { Outlast }\end{array}$} & $66 \% / 34 \%$ PP/OUT & 2,13 & 356.09 & 15,65 & 7 & 11 & 0,5874 \\
\hline & $50 \% / 50 \%$ PP/OUT & 1,96 & 279,26 & 15,75 & 8 & 13 & 0,4964 \\
\hline & $17 \% / 83 \%$ PP/OUT & 2,04 & 282.73 & 15,47 & 7 & 11 & 0,5618 \\
\hline \multirow{4}{*}{$\begin{array}{c}\text { Polipropileno / } \\
\text { Dry release }\end{array}$} & $66 \% / 34 \%$ PP/DR & 2,26 & 298.28 & 15,19 & 8 & 13 & 0,5056 \\
\hline & $50 \% / 50 \%$ PP/DR & 1,88 & 244.72 & 15,07 & 9 & 14 & 0,4370 \\
\hline & $34 \% / 66 \%$ PP/DR & 2,24 & 309,29 & 15,55 & 8 & 13 & 0,5088 \\
\hline & \begin{tabular}{|l}
$17 \% / 83 \%$ PP/DR \\
\end{tabular} & 2,13 & 255.77 & 15.00 & 9 & 14 & 0,4612 \\
\hline
\end{tabular}

Fonte: Dados da pesquisa 
$\mathrm{Na}$ estrutura jersey verifica-se, de maneira geral, que os melhores resultados na capilaridade horizontal e vertical são verificados nas combinações com PES, especialmente as produzidas com OUT. No sentido horizontal destacam-se as seguintes combinações: 83\%OUT, 66\%AQT, 50\%PBT e 34\%BA. No sentido vertical, para além dos resultados obtidos com OUT, as combinações AQT (50\% e 66\%) e BA (34\%) apresentaram igualmente bons resultados.

Relativamente à perda de umidade, as misturas com PP libertam a umidade com maior rapidez. À temperatura de $20^{\circ} \mathrm{C}$, as diferenças existentes entre as combinações com PP e PES são estatisticamente insignificantes. Sob a temperatura de $35^{\circ} \mathrm{C}$ destacam-se as misturas com PP contendo 17\%PBT, 17\%AQT e 83\%BA e com PES, $34 \%$ OUT e $66 \%$ DR.

Nas propriedades de permeabilidade - tanto ao vapor de água como ao ar - os resultados evidenciam que o melhor conjunto de valores é expresso nas malhas produzidas com PES, ressaltando-se aqueles que têm BA, OUT e DR na sua composição. Quanto à permeabilidade ao ar, as melhores performances também são obtida das malhas produzidas com PES, embora se possam destacar os resultados relativos às combinações $\mathrm{PP} / \mathrm{AQT}$.

O desempenho no cair é indiferente às combinações das malhas. De modo geral as combinações com PES apresentam os melhores resultados.

Para a construção das malhas jersey vanizado (dupla face) foram utilizados fibras de base o poliéster (PES) e o polipropileno (PP) combinadas com as fibras funcionais poliéster Coolmax $^{\circledR}, \quad$ Dry-release $^{\circledR}$, Outlast $^{\circledR}$, elastano e polibutileno ${ }^{4}$ cujas especificações se encontram no na Figura 3. No que diz respeito ao comportamento dessas malhas nos ensaios relativos às propriedades de gestão da humidade, observamse as conclusões a seguir.

\footnotetext{
${ }^{4}$ Abreviaturas: poliéster Coolmax ${ }^{\circledR}$ (PESCoo), dry-release ${ }^{\circledR}$ (DR), outlast ${ }^{\circledR}$ (OUT) elastano (EL) e polibutileno (PBT).
} 
Figura 3 - Especificações das malhas jersey vanizado

\begin{tabular}{|c|c|c|c|c|c|c|c|c|c|}
\hline \multirow[t]{2}{*}{ Malha } & \multicolumn{2}{|c|}{$\begin{array}{c}\text { Comprimento de } \\
\text { laçada }(\mathrm{cm})\end{array}$} & \multicolumn{2}{|c|}{$\begin{array}{l}\text { Massa linear do fio } \\
\text { (tex) }\end{array}$} & \multirow{2}{*}{$\begin{array}{c}\begin{array}{c}\text { Grau } \\
\text { de } \\
\text { aperto } \\
\text { (k) }\end{array} \\
\end{array}$} & \multirow[t]{2}{*}{$\begin{array}{l}\text { Massa } \\
\left(\mathrm{g} / \mathrm{m}^{2}\right)\end{array}$} & \multirow{2}{*}{$\begin{array}{c}\mathrm{N}^{\circ} \\
\text { colunas } \\
/ \mathrm{cm}\end{array}$} & \multirow{2}{*}{$\begin{array}{c}\mathrm{N}^{\circ} \\
\text { fileiras/ } \\
\mathrm{cm}\end{array}$} & \multirow{2}{*}{$\begin{array}{c}\text { Espesst } \\
\text { ra } \\
(\mathrm{mm})\end{array}$} \\
\hline & exterior & interior & exterior & interior & & & & & \\
\hline PES-EL & 15,14 & 15,78 & 11 & 2,2 & 21,91 & 126,47 & 16,0 & 19,6 & 0,87 \\
\hline PES-PESCOO & 15,73 & 15,75 & 11 & 8,7 & 21,08 & 129,90 & 14,2 & 18,4 & 1,15 \\
\hline PES-DR & 14,33 & 16,48 & 11 & 11,6 & 23,14 & 139,79 & 13,9 & 18,0 & 1,39 \\
\hline PES-OUT & 15,1 & 17,77 & 11 & 20 & 21,96 & 135,28 & 14,8 & 17,4 & 1,29 \\
\hline PES-PBT & 14,09 & 14,7 & 11 & 2,4 & 23,54 & 118,54 & 15,3 & 19,6 & 1,00 \\
\hline PP-EL & 15,24 & 15,23 & 8,7 & 2,2 & 19,35 & 128,25 & 14,8 & 23,3 & 1,21 \\
\hline PP-PESCOO & 15,19 & 15,97 & 8,7 & 8,7 & 19,42 & 121,62 & 14,1 & 19,2 & 1,21 \\
\hline PP-DR & 15,18 & 16,28 & 8,7 & 11,6 & 19,43 & 131,49 & 14,0 & 18,0 & 1,37 \\
\hline PP-OUT & 14,68 & 16,78 & 8,7 & 20 & 20,09 & 134,48 & 13,9 & 18,1 & 1,38 \\
\hline PP-PBT & 14,86 & 15,23 & 8,7 & 2,4 & 19,85 & 113,99 & 15,0 & 22,4 & 1,24 \\
\hline
\end{tabular}

Fonte: Dados da pesquisa

As malhas com a fibra OUT apresentam o melhor nível de capilaridade horizontal tanto quando molhada a face exterior, quanto quando molhada a face interior, quer seja na combinação com PES trilobal flat, quer seja com PP; verifica-se também, que, quando molhada a face interior, o comportamento da combinação PP/OUT é superior a todas as observações, principalmente nos cinco primeiros minutos.

Relativamente à capilaridade vertical, os melhores resultados são obtidos com as misturas OUT, tanto no sentido das colunas como no sentido das fileiras. As malhas com PEScoo e PBT apresentam bom desempenho nas misturas com PES em ambos os sentidos. Nas demais combinações a capilaridade pode ser considerada insignificante.

Nos ensaios de molhagem a difusão da gota de água ocorreu com mais velocidade em todas as malhas com PES. Destacam-se, principalmente, as malhas com OUT e PEScoo.

No processo de perda da umidade, verifica-se que as malhas com OUT retém mais umidade que as demais, à temperatura de $20^{\circ} \mathrm{C}$. Quando na temperatura de $35^{\circ} \mathrm{C}$, todas as combinações apresentam desempenho semelhante, libertando a umidade na mesma velocidade.

Como esperado, verifica-se que as malhas com OUT e PEScoo apresentam o melhor desempenho de gestão da humidade. Por serem fibras não naturais são 
produzidas com finalidade de melhorar a performance; a estrutura física e química do OUT favorece o comportamento em análise.

De um modo geral, as combinações com PES apresentam melhor desempenho de gestão e controle da umidade do que as com PP. Nas malhas com PES trilobal flat, pode ser atribuído um maior número de capilares entre fios e laçadas uma vez que o conjunto do fator de cobertura é superior ao das malhas com PP.

Relativamente às propriedades térmicas, as misturas com OUT e PEScoo destacam-se igualmente no nível de resistência térmica, principalmente quando combinadas com PES trilobal na face exterior, uma vez que impõem maior barreira de variação da temperatura do usuário. Contudo, as demais combinações com PP apresentam bom desempenho.

Na permeabilidade ao vapor de água todas as combinações com PES apresentam o melhor comportamento, destacando-se as que contêm OUT e PEScoo. Para a permeabilidade ao ar, as misturas com PES apresentam melhor desempenho, destacando-se as misturas com OUT e DR. Entretanto, verifica-se também que os resultados com as malhas com PP na face exterior apresentam a mesma tendência.

Nas propriedades físicas de rigidez à flexão as misturas com PES apresentam menores coeficientes o que representa melhor capacidade de flexão e de se adaptar às formas e movimentos do usuário, como também, de facilitar os processos de corte e montagem de peças do vestuário. Entretanto, na propriedade cair, algumas malhas produzidas com PP têm maior destaque.

Com base nos resultados apresentados, decidiu-se desenvolver a T-shirt com malha jersey vanizado, tendo na face exterior o fio de poliéster e na face interior, fios multifuncionais. Verificou-se, através do resultado dos questionários, as zonas de maior sudação do atleta, sua necessidade de uma T-shirt com características de libertação da umidade e de controle térmico e a possibilidade de uma peça mais justa ao corpo. Através da análise das T-shirts atualmente utilizadas pelos atletas, conclui-se que é descartada a existência de forro.

A ausência de costuras é possibilitada pela tecnologia Seamless como também, a produção de uma T-shirt com funcionalidades localizadas de acordo com as reações fisiológicas do corpo em atividade, satisfazendo a premissa de que "o equipamento influencia o desempenho do atleta". 


\subsection{O Produto}

Além das informações técnicas os dados colhidos através dos questionários aplicados aos jogadores de futebol profissional, serviram como ferramentas que nortearam a definição dos requisitos e recursos (Figura 4) necessários ao desenvolvimento do produto e que possibilitaram a definição do design da T-shirt multifuncional.

Figura 4 - Requisitos e recursos para a multifuncionalidade da T-shirt

\begin{tabular}{|c|c|}
\hline Requisito & Recurso \\
\hline $\begin{array}{l}\text { - Eliminação de costuras } \\
\text { - T-shirt junto ao corpo }\end{array}$ & Tecnologia Seamless \\
\hline $\begin{array}{l}\text { - Distribuição das funcionalidades em } \\
\text { determinadas parte do corpo }\end{array}$ & Técnica patchwork \\
\hline $\begin{array}{l}\text { - Transferência de umidade junto ao } \\
\text { corpo para o meio ambiente } \\
\text { - Combinação estética (exterior)e } \\
\text { funcionalidade (interior) }\end{array}$ & Tipo de costura \\
\hline $\begin{array}{ll}\text { - } & \begin{array}{l}\text { Prevenção da proliferação de micro- } \\
\text { organismos }\end{array} \\
\text { - } & \text { Prevenção do stress térmico } \\
\text { - } & \text { Eliminação da umidade }\end{array}$ & Materiais \\
\hline
\end{tabular}

Fonte: Dados da pesquisa

Através da produção no tear Seamless, a T-shirt foi produzida sem costuras laterais e fica colada ao corpo. Paralelo a essa tecnologia, utilizou-se o processo patchwork, o qual possibilita que as funcionalidades sejam localizadas em áreas predeterminadas. $\mathrm{O}$ jersey vanizado constitui-se numa estrutura dupla face na qual a face exterior foi trabalhada a componente estética e, a face interior, a componente funcionalidade. As diferentes combinações de fios aliadas à estrutura permitem a transferência de umidade do corpo para o exterior. Os fios utilizados com propriedades de bioatividade, 
termorregulação e controle e gestão da umidade foram distribuídos de maneira programada, a fim de que suas funcionalidades sejam maximizadas.

\subsubsection{O processo Seamless - a malha como segunda pele}

O projeto inclui processos e aspectos relativos ao design de engenharia mecânica, eléctrica, software e design industrial como a estética, a ergonomia e as interfaces com o usuário. Utilizando diversos fios através de diferentes alimentadores, a tecnologia Seamless constitui-se no processo que produz uma peça completa com o mínimo ou nenhum processo de corte e costura. Assim, reduz significativamente o tempo na produção da peça em comparação com a confecção tradicional, como também minimiza o consumo de fios através da redução do desperdício, levando à maior produtividade do sistema, sem considerar que, na confecção tradicional, as aparas de tecidos são grandes fontes de desperdício.

A unificação do processo de produção do vestuário simplifica a confecção da peça e, neste caso, pode-se dizer que a T-shirt nasce com a malha. Essa qualidade agrega-se à elasticidade e à maleabilidade do material com as quais se pode conseguir a adaptação de forma à anatomia do corpo.

Considerado uma segunda pele, deve-se perceber a sua duplicidade: por dentro fornece a espacialidade básica e mais imediata do corpo e, por fora, funciona como um novo contorno. Reunir e valorizar os recursos construtivos como funcionalidades, características ergonómicas e beleza estética permitem explorar a versatilidade morfológica de uma peça. O movimento durante o uso incide na transformação de uma determinada forma, principalmente sobre o vestuário. Este se transforma conjuntamente com o movimento do corpo em função de fatores circunstanciais ao movimento, tais como dinâmica, energia, trajetória e tempo, em diferentes níveis e direção.

\subsubsection{Conceito patchwork}

O conceito patchwork presente nesta peça, caracterizada pela existência de diferentes zonas em termos de materiais utilizados numa mesma estrutura fibrosa, tornase possível devido ao tipo de tecnologia utilizada para a produção da mesma. Esta tecnologia, de malha de trama circular Seamless, apresenta, além de mecanismos especiais ao nível da própria máquina, um software de realização de desenhos (sistema 
CAD), que possibilita a execução de programas onde podem ser determinadas diferentes zonas bem definidas. As zonas comportam materiais diferentes e/ou estruturas de malha diferentes, no sentido de se maximizar determinada função.

As funcionalidades apresentadas pela T-shirt desportiva são controle da proliferação/aparecimento de micro-organismos causadores de infecções e micoses, e a gestão da umidade e da temperatura, localizadas de acordo com a necessidade fisiológica da parte do corpo.

\subsection{Design}

A Figura 5 ilustra a localização das funcionalidades na T-shirt desportiva. A face exterior da T-shirt é integralmente produzida com fio PES com seção transversal trilobal, no sentido de permitir o rápido transporte e evaporação da humidade para o exterior. A face interior, composta por vários fios funcionais, está descrita a seguir.

\section{Figura 5 - Design Proposto para a T-shirt - visão frontal e visão posterior}

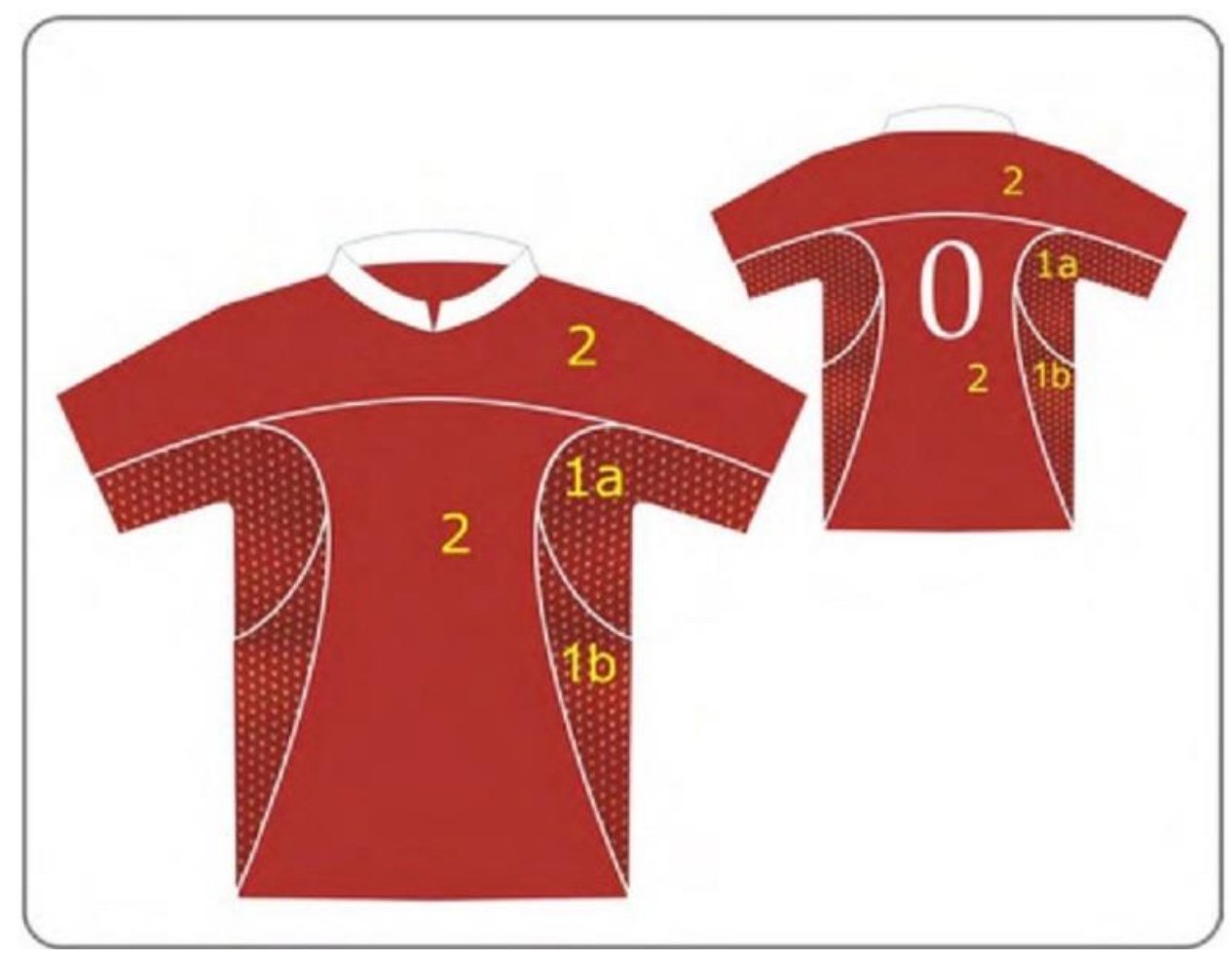

Tal como se pode verificar a T-shirt se encontra dividida em três áreas distintas, nas quais estrutura e funcionalidades definem a construção de cada uma destas: 
Áreas 1a e 1b - Estrutura jersey vanizado aberta, com fator de cobertura inferior à área 2, ao nível de $30 \%$. Face exterior em poliéster, e face interior dividida em duas áreas funcionais $1 \mathrm{a}$ e $1 \mathrm{~b}$.

Área 1a - Face exterior em fio de poliéster e face interior contendo fio de fibra bioativa. Essa área engloba toda a zona da axila e é normalmente caracterizada pela elevada produção de suor do atleta pelo que, nesta área, são utilizados fios formados por fibras bioativas e de gestão de umidade, no sentido de permitir rápido transporte do suor gerado para o exterior e evitar o aparecimento de fungos e bactérias. Por outro lado, nesta zona a malha apresenta-se numa estrutura mais aberta, ou seja, com menor grau de aperto.

Área1b - Face exterior em poliéster e face interior contendo fio com propriedade de gestão de umidade. Nesta zona as laçadas produzidas com fios com propriedades de gestão de umidade favorecem a evaporação da umidade, enquanto a estrutura de malha mais aberta, tal como na área anterior, permite maior penetração do ar no microclima. Área 2 - Face exterior contendo fio em poliéster, e face interior com fio de fibra com propriedade de termorregulação. Esta área, a maior, engloba a zona do tronco frontal e posterior, com estrutura formada por laçadas normais e com fator de cobertura maior que nas restantes áreas descritas. Nesta área os fios são formados por fibras com características termorreguladoras e de gestão de umidade.

As Figuras 6 e 7 apresentam o design estético da T-shirt com as suas variações. 


\section{Figura 6 - Design visual da T-shirt proposta}

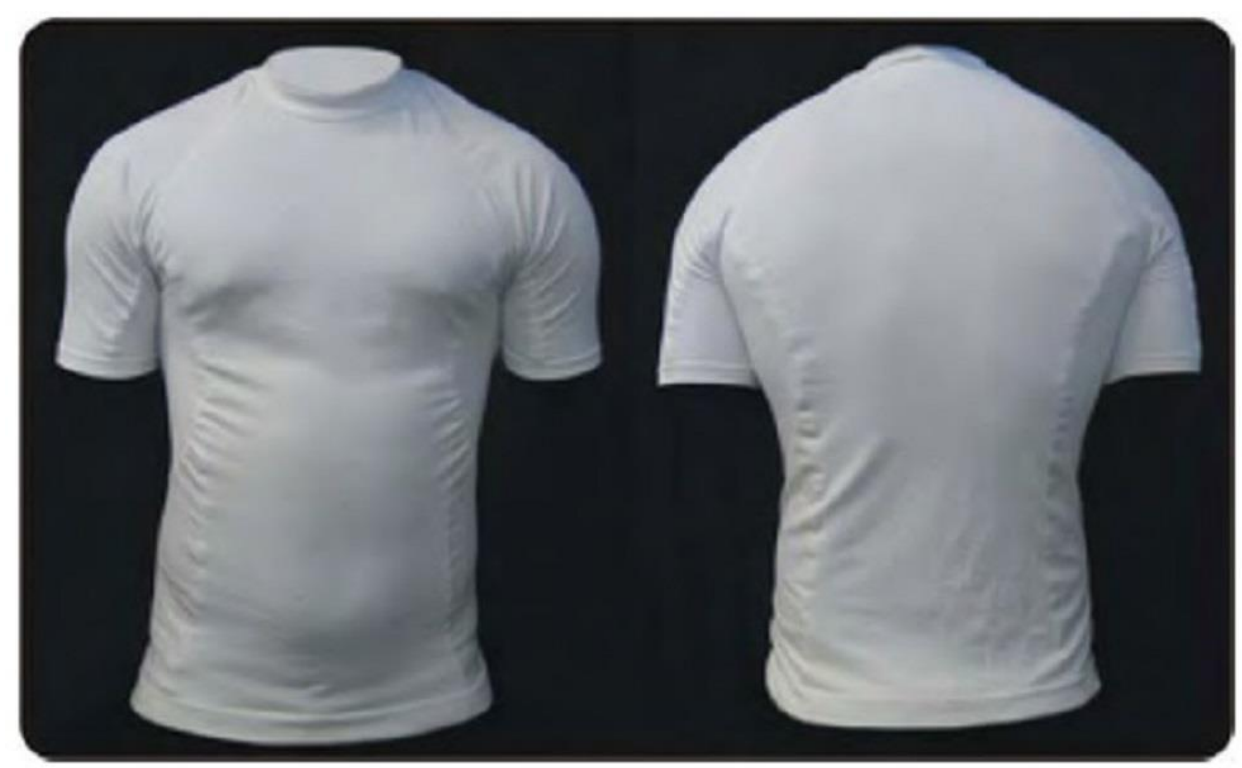

Figura 7 - Variações da T-shirt multifuncional

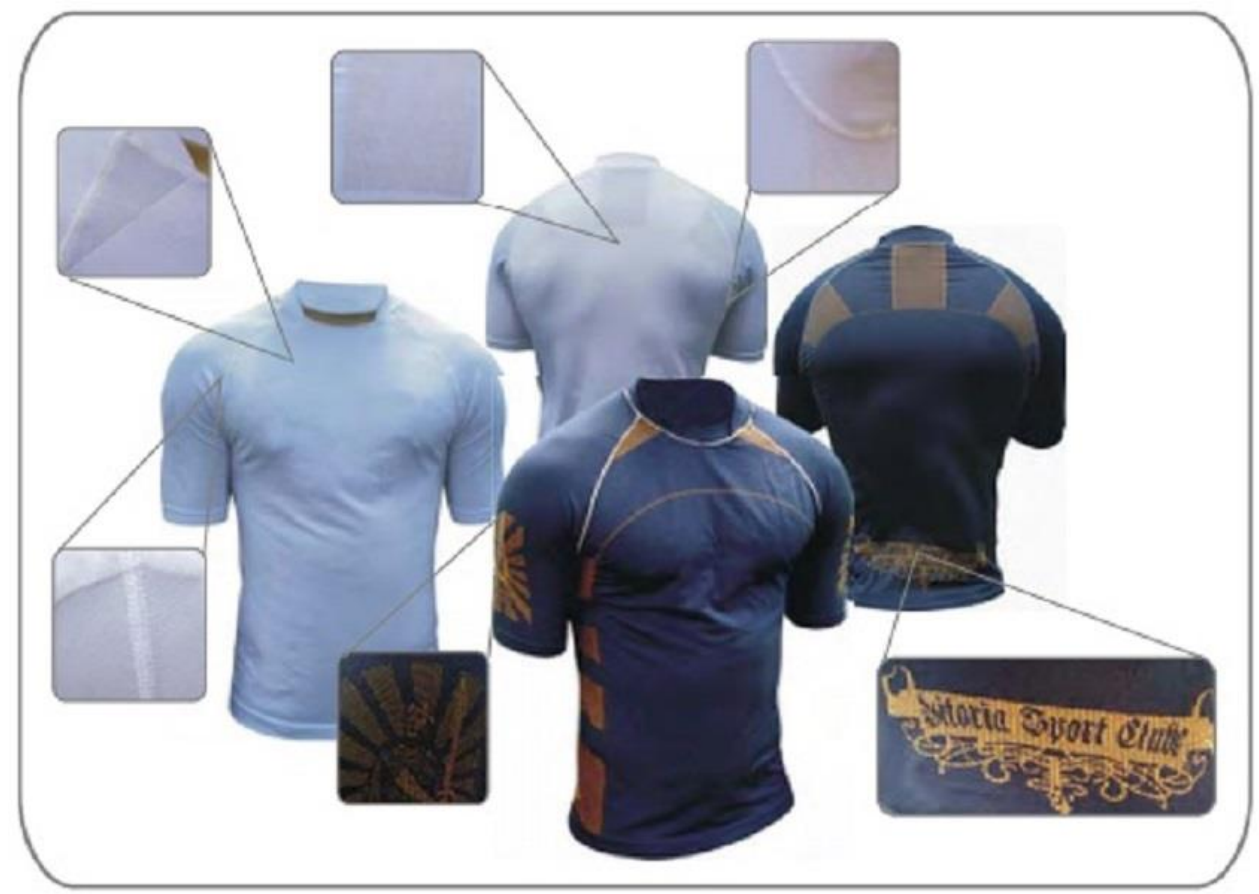

A T-shirt desenvolvida busca apresentar ao mercado um produto inovador, que forneça ao utilizador características únicas: uma T-shirt na qual diversas funcionalidades estão distribuídas de acordo com as reações fisiológicas do corpo 
humano na sua face interior, e que na face exterior se possa aliar funcionalidade ao colorido vibrante que o desporto requer, e ainda produzida sem costura.

\section{CONCLUSÃO}

Para a indústria de produtos desportivos o conforto e o desempenho funcional transformaram-se em elementos de vantagem competitiva no mercado global. Estes aspectos têm sido identificados como os atributos mais importantes e procurados pelos consumidores, especialmente em situações de uso dinâmico. Tendo sido notado que, no segmento desportivo, esse enfoque vem crescendo em detrimento do estilo, e em algumas vezes considerado como de importância secundária, é sabido que o aspecto estético é o que em primeira instância atrai o consumidor.

No final deste trabalho, pode concluir-se que propiciar conforto às pessoas nos dias atuais, é uma tarefa que todo profissional deve permear na sua prática diária, especialmente quando trabalha com o desenvolvimento de produtos do vestuário. Para o designer, esse aspecto é fundamental e imprescindível, tendo em conta que o usuário tem que sentir conforto tanto pela face interna assim como pela face externa do vestuário, ou seja, o conforto fisiológico e o conforto psicológico, os quais o permitem sentir-se inteiramente à vontade.

Com este trabalho buscou-se propiciar maior conforto aos jogadores de futebol profissional através da concepção de uma T-shirt tecnológica. Fios funcionais foram localizados estrategicamente, tendo em conta as necessidades do corpo de acordo com suas reações fisiológicas durante a prática desportiva. Os recursos tecnológicos favoreceram a investigação e o produto final disponível para a compreensão do seu desenvolvimento. Esta pode ser considerada uma investigação de sucesso, uma vez que, durante o seu decorrer, as empresas de produção e comercialização envolvidas desenvolveram uma T-shirt baseada no conceito deste Projeto.

Artigo recebido em Julho de 2015. Aprovado em Setembro de 2015

DOl:http://dx.doi.org/105965/1982615x08172016195 


\section{Referências bibliográficas}

ACCIOLLY, A. Marcas de valor no mercado brasileiro. Editora Senac: São Paulo, 2000.

ALMEIDA, B. S. de; NUNES, R. J. S.; VLASTUIN, J. Existe marketing esportivo olímpico no Brasil? Considerações sobre as inter-relações COB e Governo Federal no contexto brasileiro. In: $1^{\circ}$ ENCONTRO DA ALESDE Esporte na América Latina: atualidade e perspectivas. Curitiba-Paraná- Brasil: Universidade Federal do Paraná, 2008 .

ARAÚJO, M. S. de. Design de vestuário para desportistas deficientes motores [Dissertação de mestrado]. Guimarães, Portugal: Universidade do Minho. 2009.

ARAÚJO, M. S. de. Design de vestuário adaptado a jogadores de basquetebol deficientes motores: aspectos beneficentes da satisfação de necessidades especiais. In: XV ENCONTRO DE CIÊNCIAS SOCIAIS DO NORTE E NORDESTE e PRÉ-ALAS BRASIL. ANAIS: Grupo de Trabalho: [GT 2: Ciências Sociais e Esporte: conjugando abordagens e perspectivas em um campo de pesquisa plural e interdisciplinar]. UFPI: Teresina-PI, 2012.

AZEVÊDO, P. H. O esporte como negócio: uma visão sobre a gestão do esporte nos dias atuais. In: Estudos. Goiânia, v. 36, n. 9/10, p. 929-939, set./out. 2009.

BARNARD, M. Moda e comunicação. Rio de Janeiro: Rocco, 2003.

BOURG, J. F.; GOUGUET, J.J. Economia do esporte. Trad. Maria Leonor Loureiro. Bauru, SP: Edusc, 2005.

BROEGA, A. C.; SILVA, Maria E. O conforto total do vestuário: design para os cinco sentidos. Actas de Diseño, no 9, Ano 5, Julho 2101. Palermo, Argentina, p. 59-61.

CUNHA. J. Ciência do conforto. Guimarães: Universidade do Minho. 2006.

CASTELLANI FILHO, L. MEGAEVENTOS ESPORTIVOS NO BRASIL: de expressão da política esportiva brasileira para a da concepção neodesenvolvimentista de planejamento urbano In: Motrivivência v. 26, n. 42, p. 98-114, junho/2014.

FILGUEIRAS, A. P. A. Optimização do design total de malhas multifuncionais para utilização em vestuário desportivo. [Tese de Doutorado]. Guimarães, Portugal: Universidade do Minho, 2008. 
FILGUEIRAS, A. P. A.; FANGUEIRO, R.; RAPHAELLI, N. A importância de fibras e fios no design de têxteis destinados à prática desportiva. In: Estudos em Design 15.1. Rev. da Associação Estudos em Design PUC-Rio, 2008.

HALL, JE e GUYTON, A. Tratado de fisiologia médica. Rio de Janeiro, Guanabara Koogan, 2002, pp. 1167-1179.

HELAL, R.; GORDON, C.. Futebol: mitos e representações do Brasil. In: VILLAÇA, N. e GÓÉR, F. (Eds.) Nas fronteiras do contemporâneo: território, identidade, arte, moda, corpo e mídia. Rio de Janeiro: Mauad, 2001.

KASZNAR, I. Projeções da conta satélite do produto interno bruto esportivo - Proxy PIB, Renda per capita, Crescimento e Impostos. In: Eletro Revista - Revista Cientifica e Tecnológica: IBCI - Institutional Business Consultoria Internacional. Mês: Julho - n. 64. 2013.

KOTLER, P. \& BES, F.T. de. Marketing lateral. Rio de Janeiro: Editora Elsevier, 2004.

KOTLER, P. Administração de marketing. 12ed. São Paulo: Pearson Education do Brasil, 2005.

LI, Y. The objective assessment of comfort of knitted sportswear in relation to psychophysiological sensory studies. Leeds: The University of Leeds, PhD Thesis. IN: Y. Li. 1999.Science of clothing comfort. Textile Progress, 1998.

MELO, V. A. de; RESENDE, F.; PALMA, A. ASSIS, M.. A carne mais barata do mercado é a carne negra uma reflexão sobre o "design" das camisas da puma na copa do mundo de futebol/2010. In: Rev. Bras. Educ. Fís. Esporte, São Paulo, v.25, n.2, p.313322, abr./jun. 2011.

PAULICO, F. A. A. Marketing desportivo no pódio. In: Gestin: Instituto Politécnico de Castelo Branco- PT. Escola Superior de gestão, Ano VII- n. 7 p.113-121, dez. 2008.

PIRES, D. B. (Org.). Design de moda: olhares diversos. São Paulo: Estação das Letras, 2008.

RODRIGUES, F. X. F. et al. Análise sobre os legados da Copa do Mundo FIFA 2014 em Cuiabá/MT. In: PercursoAcadêmico, Belo Horizonte, v. , n.8, jul./dez. 2014. SÁ, C. \& SÁ, D. Marketing para desporto: um jogo empresarial. Edições IPAM: Porto. 2002. 
SHISHOO, R. Textiles in sport. New York: Woodhead Publishing Textiles, 2005, p. 111.

SLATER, K. The assessment of comfort. In: The Journal of the Textile Institute. 1986. vol. $77, \mathrm{n}^{\mathrm{o}} 3$.

SLATER, K. Subjective textile testing. In: The Journal of the Textile Institute. 1997. vol 88 Part $1, \mathrm{n}^{\circ} 2$.

SOUZA, J. M. Design de malhas multifuncionais para aplicação técnicas. [Tese de mestrado] Guimarães, Portugal: Universidade do Minho. 2008. 